\title{
Computational screening and identifying binding interaction of anti-viral and anti-malarial drugs: Toward the potential cure for SARS-CoV-2.
}

\author{
Vannajan Sanghiran Lee ${ }^{1 *}$, Wei Lim Chong ${ }^{1}$, Sri Devi Sukumaran ${ }^{1}$, Piyarat Nimmanpipug ${ }^{2}$, Vengadesh \\ Letchumanan $^{3}$, Bey-Hing Goh ${ }^{4}$, Learn-Han Lee ${ }^{3}$, Sharifuddin Md. Zain ${ }^{1}$, Noorsaadah Abd Rahman ${ }^{1}$ \\ ${ }^{1}$ Department of Chemistry, Drug Design and Development Research Group (DDDRG), Centre for Theoretical and Compu- \\ tational Physics, Faculty of Science, University of Malaya, 50603 Kuala Lumpur, Malaysia. \\ ${ }^{2}$ Department of Chemistry, Faculty of Science and Center of Excellence for Innovation \\ in Analytical Science and Technology, Chiang Mai University, 50200, Chiang Mai, Thailand. \\ ${ }^{3}$ Novel Bacteria and Drug Discovery Research Group (NBDD), Microbiome and Bioresource Research Strength (MBRS), \\ Jeffrey Cheah School of Medicine and Health Sciences, Monash University Malaysia, 47500 Bandar Sunway, Selangor \\ Darul Ehsan, Malaysia. \\ ${ }^{4}$ Biofunctional Molecule Exploratory Research Group (BMEX), School of Pharmacy, Monash University Malaysia, 47500 \\ Bandar Sunway, Selangor Darul Ehsan, Malaysia.
}

\begin{abstract}
Since the emergence of 2019 novel coronavirus (also known as SARS-CoV-2) to date, effective treatment for the patients was reported to be some anti-viral for flu and HIV-1 or anti-malaria drugs. To understand the finer details of the molecular interactions and complexation between these proteinase inhibitors and the COVID-19, virus sequence analysis in comparison to SARS coronavirus and molecular docking were carried out. Results showed-favourable binding for the current treatment of drugs and 7 additional possible effective drugs, DB06290 (Simeprevir, Hepatitis C drug), DB09183 (Dasabuvir, Hepatitis C drug), DB01232 (Saquinavir, HIV-1 drug), DB00254 (Doxycycline, Malaria drug), DB01117 (Atovaquone, Malaria drug), DB04835(Maraviroc, HIV-1 drug), DB08930 (Dolutegravir, Hepatitis C drug) with good binding affinities towards COVID-19 in the range of -8.7 to $-8.0 \mathrm{kcal} / \mathrm{mol}$. Analysis of the interaction residues of the docked complex was mapped in a 2D diagram to explain the interaction with the proteinase binding pocket. Repurposed drugs from our recommendation may help battle the new coronavirus and subject for additional examination.
\end{abstract}

Keywords: SARS-CoV-2; Anti-viral; HIV-1, Anti-malaria; COVID-19, Molecular Docking

Received: $24^{\text {th }}$ February 2020

Accepted: $24^{\text {th }}$ March 2020

Published Online: $26^{\text {th }}$ March 2020
*Correspondence: Vannajan Sanghiran Lee, Department of Chemistry, Drug Design and Development Research Group (DDDRG), Centre for Theoretical and Computational Physics, Faculty of Science, University of Malaya, 50603 Kuala Lumpur, Malaysia; vannajan@um.edu.my

Citation: Lee VS, Chong WL, Sukumaran SD, et al. Computational screening and identifying binding interaction of anti-viral and anti-malarial drugs: Toward the potential cure for SARS-CoV-2. Prog Drug Discov Biomed Sci 2020; 3(1): a0000065. https://doi.org/10.3687/pddbs.a0000065

\section{Introduction}

Novel coronavirus 2019-CoV poses a very grave threat to the global community. The Chinese authorities are scrambling to find the mysterious cause of this virus that emerged in early December 2019 ${ }^{[1]}$. Cluster cases of coronavirus-induced pneumonia was notified to World Health Organization (WHO)'s Chinese office on $31^{\text {st }}$ December 2019, which resulted in closing of Huanan Seafood Wholesale Market on $1^{\text {st }}$ January $2019^{[1]}$. On $11^{\text {th }}$ February 2020, WHO officially named this virus as COVID-19 ${ }^{[2]}$.

The COVID-19 shares the similar coronavirus family tree with Severe Acute Respiratory Syndrome (SARS) that infected 8,096 people and 744 deaths in 2002-2003 ${ }^{[3]}$. There are several genome sequence of COVID-19 that been deposited on GenBank and Global Initiative on Sharing All Influenza data (GISAID) ${ }^{[4,5]}$. The sequence information revealed COVID-19 belongs to betacoronavirus originated from bats. However, the exact wildlife host as virus reservoir is yet to be confirmed as many live animals were sold at the market, where the virus originated and transmitted ${ }^{[6,7]}$. There is an ongoing debate on possible wildlife host, either bats or snakes based on the complete genome analysis. Recently, scientist reported 
that pangolins could act as intermediate host to pass the virus to humans. Its science is still suggestive rather than conclusive $^{[8]}$.

COVID-19 has emerged into an epidemic that paralyzed many provinces in China, and still on rise. Wuhan and several other cities across China were completed lockdown with aim to control and contain the spread of the virus $^{[9]}$. This fast-spreading COVID-19 has claimed 1115 lives and infected over 80,000 people in 37 countries (as of $25^{\text {th }}$ February 2020 ${ }^{[10]}$. Hubei, the worst hit province in China recorded over 64,000 infected cases and 2560 death $^{[11]}$. In Thailand, a total of 37 infected cases have been detected and 21 patients recovered from the virus infection. The virus has a transmission rate (Ro) of 3 (2-3 newly infected from 1 case) with $2 \%$ fatality rate $(\mathrm{CFR})^{[11]}$. While parts of China begin to lower their emergency response level, the coronavirus is spreading more quickly to other parts of the world, Middle East, Europe, Latin America. More deaths have been reported in Iran and Italy ${ }^{[13-14]}$. In addition, experts have declared 24 days incubation period for COVID-19 rather than the previously believed 14 days, based on the clinical symptoms presented by the patients ${ }^{[12]}$.

The community raises concern on COVID-19 as transmission to other countries besides China is mainly by people who had travelled from outbreak area or had close contact with an infected person. The Chinese along with WHO implemented precaution measures to control the spread of this virus. In the process of rapid identification, BGI Group has been granted the approval to manufacture and sell two virus detection kits and a sequencing system $^{[15]}$. The community too are aware of the precaution and hygiene measures to avoid been infected with COVID-19.

Now researchers and scientists are racing against time to discover an effective drug or vaccine to treat the flu caused by this coronavirus. Doctors in Thailand reported to have successfully treated a 71-year-old patient with a cocktail of antivirals that are used to treat flu (oseltamivir) and HIV (lopinavir and ritonavir) ${ }^{[16]}$. Malaysia also has some cases which cured patients with treatment of antiviral medicine, Kaletra (a commercial name for lopinavir) ${ }^{[17]}$. Likewise, in the United States (US), doctors administrated remdesivir to treat a 35-year-old patient and his symptoms improved. Remdesivir is a Gilead Sciences drug that been used for emergency treatment of patients with Ebola ${ }^{[18]}$. Further tests should be done in order to confirm the effectiveness of these antivirals.

Virtual in silico screening has repeatedly proven to be useful to meet the special challenges of antiviral drug discovery (Figure 1). Recently, four antiviral drugs (Nelfinavir, oseltamivir, lopinavir, ritonavir $)^{[19,20]}$ and antimalaria drug, Chloroquine Phosphate, have been reported to be effective ${ }^{[21]}$. A combination of HIV (lopinavir and ritonavir) and flu (oseltamivir, commercial name as Tamiflu) drugs for the treatment of patients infected with the new coronavirus has been used at Rajavithi Hospital in Bangkok, Thailand and gives a better outcome.

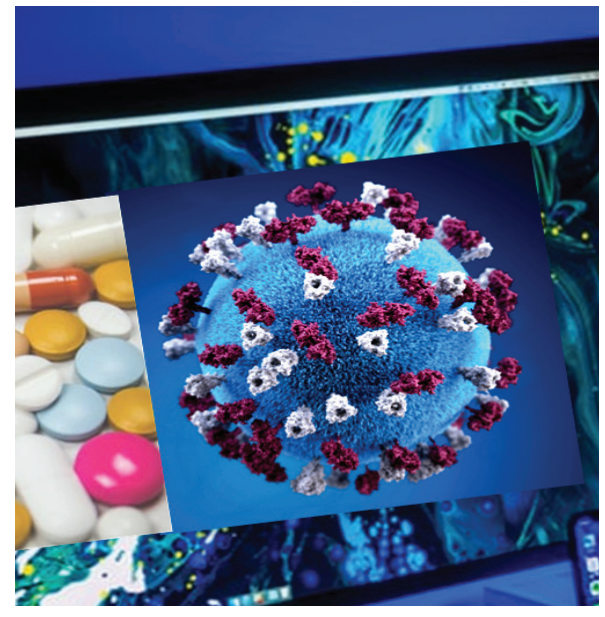

Figure 1. Modern drug discovery using in silico screening techniques in the search of anti-viral and anti-malarial drugs for COVID-19 (created from royalty free images from https://www.shutterstock.com/).

Our previous work on severe acute respiratory syndrome (SARS) during the outbreak in 2003 indicated the primary key enzyme, coronavirus proteinase, to be a good target for designing and screening for anti-SARS drug ${ }^{[22]}$. In this paper we compare the genetic sequence of SARS-CoV and COVID-19 main proteinase and explored the potential uses of anti-viral and anti-malarial approved FDA drugs to gain insights and understanding on the binding interactions for COVID-19.

\section{Methods}

\section{Computational details}

\section{Protein target and drug models}

The crystal structure of 2019-nCoV main proteinase in complex with a peptide-like inhibitor N3 (PDB ID: 6LU7) and the structure of SARS Coronavirus (SARS CoV) Main Proteinase (PDB ID: 1Q2W) were retrieved from protein databank. Protein X-ray crystal structures were first prepared under Discovery Studio programme v4.5 (Accelrys Inc., San Diego, CA, USA), with heteroatoms including waters and ions removed. Missing residues, ${ }^{45} \mathrm{TAED}^{48}$ in chain A and ${ }^{46} \mathrm{AEDMLN}^{51}$ in chain B of SARS proteinase were added to close the gap. Proteins were then minimized with 500 steps of steepest descent and 500 steps of conjugate gradient in the presence of water and ions using AMBER14 forcefield ${ }^{[23]}$. The protein sequence were analyzed using Discovery Studio programme v4.5 and the protein conformational dynamics based on contact topology in a coarse-grained presentation were compared using Gaussian Network Model (GNM, http://enm.pitt. $\mathrm{edu} /)^{[24-26]}$ to observe overall protein flexibility.

49 Approved FDA anti-viral drugs (Table 1), 2 experimental anti-viral drugs (Table 1), and 16 anti-malarial drugs (Table 2) in 3D-SDF file format were downloaded from DrugBank ${ }^{[27]}$ for screening. Drug models were retrieved from protein databank (PDB) if no available 3DSDF file was found in DrugBank database. 


\section{Molecular docking and Interaction analysis}

Molecular docking was performed with local search algorithm using Autodock Vina in PyRx virtual screening software (http://pyrx.scripps.edu/). PyRx with easy-to-use user interface can be used to screen libraries of compounds for computational drug discovery against potential drug targets and enables to run in any platform and helps users in every step of the drug discovery process - from data preparation to job submission and analysis of the results. The amino acid binding site located at His41 and Cys145 was selected as the binding center with the box size about 30.0 x 40.0 x $30.0 \AA$. The Ghemical force field is similar to the Tripos-5.2 force field method which performs acceptably on providing geometries of organic-like molecules. The docked complex is then mapped to clarify the interacting residues using PoseView ${ }^{[28]}$ (Wallace AC, 1995).

Table 1. Details on antiviral FDA approved drugs in this study.

\begin{tabular}{|c|c|c|}
\hline DrugBank ID & Drug name & Target \\
\hline DB00194 & Vidarabine & Human Herpesvirus 1, Human Herpesvirus 3, Human Herpesvirus 4 \\
\hline DB00198 & Oseltamivir & Influenza A Virus, Influenza B Virus \\
\hline DB00220 & Nelfinavir & Human Immunodeficiency Virus 1 \\
\hline DB00224 & Indinavir & Human Immunodeficiency Virus 1, Human T-Lymphotropic Virus 1 \\
\hline DB00238 & Nevirapine & Human Immunodeficiency Virus 1 \\
\hline DB00249 & Idoxuridine & Human Herpesvirus 1 \\
\hline DB00299 & Penciclovir & Human Herpesvirus 1 \\
\hline DB00369 & Cidofovir & Human Herpesvirus 5 \\
\hline DB00426 & Famciclovir & Human Herpesvirus 1, Human Herpesvirus 3 \\
\hline DB00432 & Trifluridine & Human Herpesvirus 1 \\
\hline DB00442 & Entecavir & Hepatitis B Virus \\
\hline DB00478 & Rimantadine & Influenza A Virus \\
\hline DB00495 & Zidovudine & Human Immunodeficiency Virus 1 \\
\hline DB00503 & Ritonavir & Human Immunodeficiency Virus 1 \\
\hline DB00529 & Foscarnet & Human Herpesvirus 1, Human Herpesvirus 5 \\
\hline DB00558 & Zanamivir & Human Parainfluenza Virus 3, Influenza A Virus, Influenza B Virus \\
\hline DB00577 & Valaciclovir & Human Herpesvirus 1 \\
\hline DB00625 & Efavirenz & Human Immunodeficiency Virus 1 \\
\hline DB00649 & Stavudine & Human Immunodeficiency Virus 1 \\
\hline DB00701 & Amprenavir & Human Immunodeficiency Virus 1, Human Immunodeficiency Virus 2 \\
\hline DB00705 & Delavirdine & Human Immunodeficiency Virus 1 \\
\hline DB00709 & Lamivudine & Hepatitis B Virus, Human Immunodeficiency Virus 1 \\
\hline DB00718 & Adefovir Dipivoxil & Hepatitis B Virus \\
\hline DB00787 & Aciclovir & Human Herpesvirus 1, Human Herpesvirus 3 \\
\hline DB00811 & Ribavirin & Hepatitis C Virus, Human Parainfluenza Virus 2, Influenza A Virus, Influenza B Virus, Respiratory Syncitial Virus \\
\hline DB00879 & Emtricitabine & Human Immunodeficiency Virus 1 \\
\hline DB00900 & Didanosine & Human Immunodeficiency Virus 1 \\
\hline DB00915 & Amantadine & Influenza A Virus \\
\hline DB00943 & Zalcitabine & Human Immunodeficiency Virus 1 \\
\hline DB01004 & Ganciclovir & Human Herpesvirus 1 \\
\hline DB01048 & Abacavir & Human Immunodeficiency Virus 1 \\
\hline DB01072 & Atazanavir & Human Immunodeficiency Virus 1 \\
\hline DB01232 & Saquinavir & Human Immunodeficiency Virus 1 \\
\hline DB01264 & Darunavir & Human Immunodeficiency Virus 1, Human Immunodeficiency Virus 2 \\
\hline DB01265 & Telbivudine & Hepatitis B Virus \\
\hline DB01319 & Fosamprenavir & Human Immunodeficiency Virus 1 \\
\hline DB01601 & Lopinavir & Human Immunodeficiency Virus 1 \\
\hline DB01610 & Valganciclovir & Human Herpesvirus 5 \\
\hline DB04835 & Maraviroc & Human Immunodeficiency Virus 1 \\
\hline DB05521 & Telaprevir & Hepatitis C Virus, Respiratory Syncitial Virus \\
\hline DB06290 & Simeprevir & Hepatitis C Virus, Respiratory Syncitial Virus \\
\hline DB06414 & Etravirine & Human Immunodeficiency Virus 1 \\
\hline DB06614 & Peramivir & Influenza A Virus, Influenza B Virus \\
\hline DB06817 & Raltegravir & Human Immunodeficiency Virus 1 \\
\hline DB08864 & Rilpivirine & Human Immunodeficiency Virus 1 \\
\hline
\end{tabular}


Computational screening...

\begin{tabular}{lll}
\hline DB08873 & Boceprevir & Hepatitis C Virus, Respiratory Syncitial Virus \\
\hline DB08930 & Dolutegravir & Human Immunodeficiency Virus 1 \\
\hline DB08934 & Sofosbuvir & Hepatitis C Virus, Respiratory Syncitial Virus \\
\hline DB09183 & Dasabuvir & Hepatitis C Virus \\
\hline DB12466 & Favipiravir & Experimental, Novel coronavirus \\
\hline DB14761 & Remdesivir & Experimental, Novel coronavirus
\end{tabular}

Note:The drugs in highlighted were reported as the current treatment for patients infected with the novel coronavirus.

Table 2. Details on 16 current anti-malarial FDA approved drugs recognized in Plasmodium falciparum.

\begin{tabular}{ccc}
\hline DrugBank ID & Drug name & Drug class \\
\hline DB00205 & Pyrimethamine & Diazines \\
\hline DB00207 & Azithromycin & Macrolides and analogues \\
\hline DB00254 & Doxycycline & Quinolines and derivatives \\
\hline DB00358 & Mefoquine & Cinchona alkaloids \\
\hline DB00468 & Quinine & Experimental, Novel \\
\hline DB00608 & Chloroquine & Coronavirus \\
\hline DB00613 & Amodiaquine & Tetracyclines \\
\hline DB00759 & Tetracycline & Cinchona alkaloids \\
\hline DB00908 & Quinidine & Naphthalenes \\
\hline DB01087 & Primaquine & Diazines \\
\hline DB01117 & Atovaquone & Carboxylic acids and derivatives \\
\hline DB01131 & Proguani, & Phenanthrenes and derivatives \\
\hline DB01190 & Clindamycin & Benzene and derivatives \\
\hline DB01218 & Halofantrine & Lipids and lipid-like molecules \\
\hline DB01299 & Sulfadoxine, & Artemisinin \\
\hline DB13132 &
\end{tabular}

Note: The drug in highlighted was reported as the current treatment for patients infected with the novel coronavirus.

\section{Results and discussion}

Sequence alignment of SARS CoV and COVID-19 proteinase were shown in Figure 2 beginning from amino acids residue 3 to 301 and 1 to 306 , respectively. Threedimensional structures superimposed in Figure 3 indicated twelve different positions in amino acids sequence between SARS CoV and COVID-19 proteinase. These positions involve three polar, seven non-polar, two +charge and one -charge amino acids. There is a change in amino acid residue in the binding pocket from alanine (nonpolar in SARS CoV) to serine (polar in COVID-19) at position 46. Several other positions would be less electrostatic owing to replacement of polar by nonpolar group e.g. threonine to valine at residue 35 , serine to alanine at residue 94, histidine to phenylalanine at residue 134 , and threonine to alanine at residue 285.

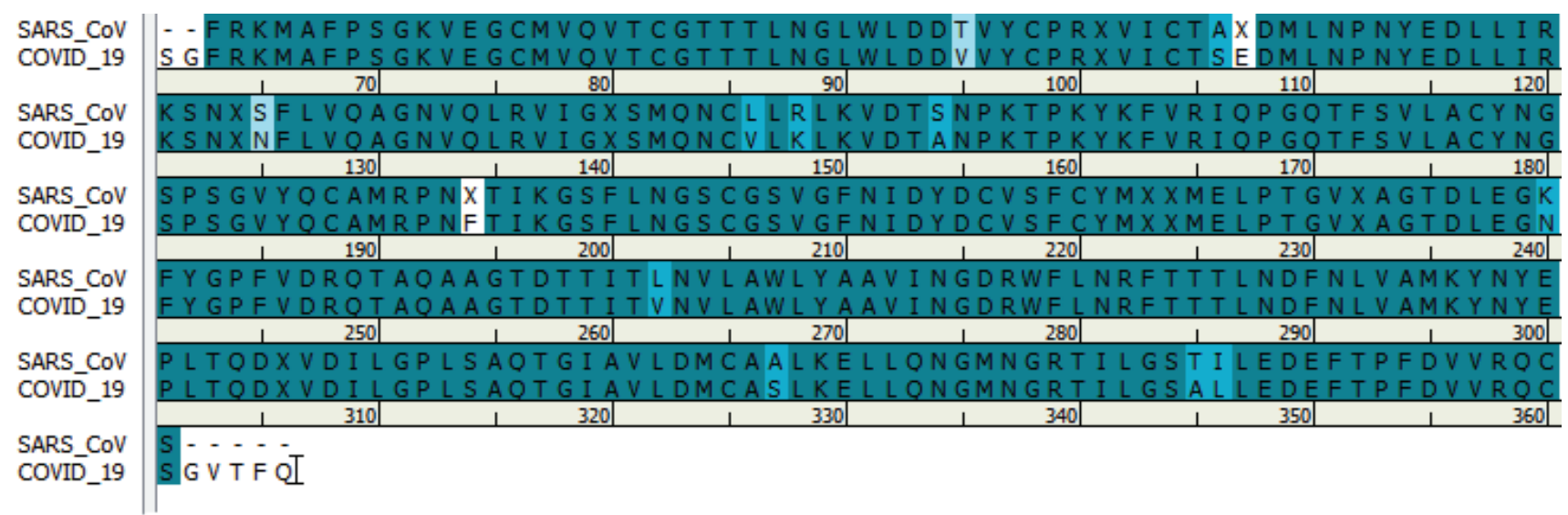

Figure 2. Sequence alignment of proteinase of SARS and COVID-19. Image was generated by Discovery Studio v4.5 where X at the position 46 is protonated glutamine and at the position 136 is Histidine residue 


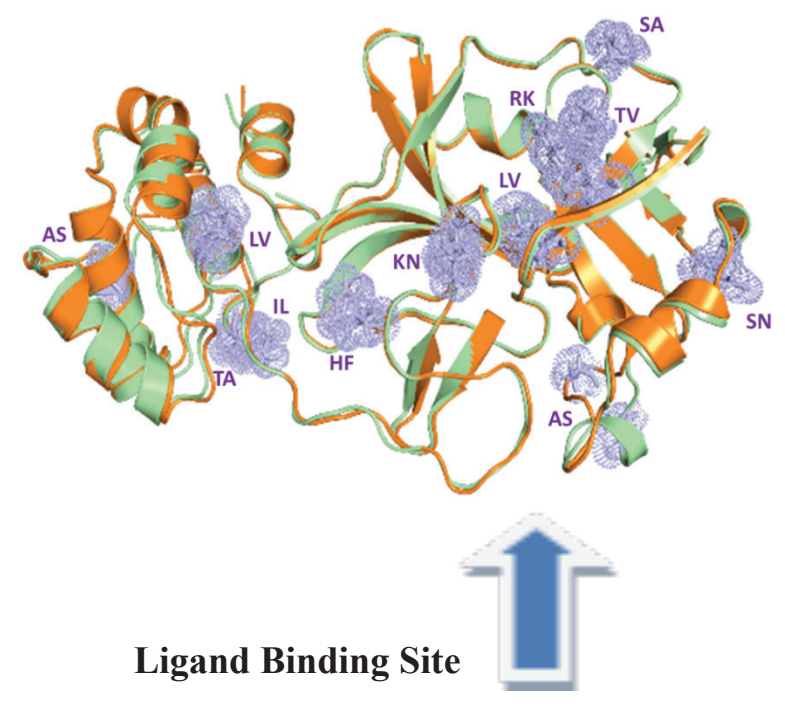

\begin{tabular}{|c|c|c|}
\hline Position & $\begin{array}{l}\text { SARS-CoV } \\
\text { proteinase }\end{array}$ & $\begin{array}{c}\text { COVID-19 } \\
\text { proteinase }\end{array}$ \\
\hline 35 & $\mathbf{T}$ & $\mathbf{v}$ \\
\hline 46 & $\mathbf{A}$ & $\mathbf{s}$ \\
\hline 47 & H & E \\
\hline 65 & $\mathbf{s}$ & $\mathbf{N}$ \\
\hline 86 & $\mathbf{L}$ & $\mathbf{v}$ \\
\hline 88 & $\mathbf{R}$ & $\mathbf{K}$ \\
\hline 94 & $\mathbf{s}$ & $\mathbf{A}$ \\
\hline 134 & H & $\mathbf{F}$ \\
\hline 180 & $\mathbf{K}$ & $\mathbf{N}$ \\
\hline 202 & $\mathbf{L}$ & $\mathbf{v}$ \\
\hline 267 & A & $\mathbf{s}$ \\
\hline 285 & $\mathbf{T}$ & $\mathbf{A}$ \\
\hline 286 & I & $\mathbf{L}$ \\
\hline
\end{tabular}

Polar, nonpolar, +charge, -charge

Figure 3. Superimposed proteinase of COVID-19 proteinase (cyan green) to SARS CoV proteinase (orange). Positions of amino acids varied in the two proteinase were surrounded by dots with the amino acids side chain showed in stick model. Amino acids letter code described the change of amino acids, of SARS CoV proteinase to COVID-19 proteinase. Image was generated by Pymol.
In agreement with the GNM model, the binding site of SARS-CoV and COVID-19 proteinase exhibited different flexibilty. Mean-square fluctuation of residues can be predicted from theoretical B-factor $\left(\AA^{2}\right)$ in Figure 4. COVID-19 have higher flexibility in the binding site than SAR-CoV. Different activity of drugs could be observed due to this difference in binding toward the binding pocket.

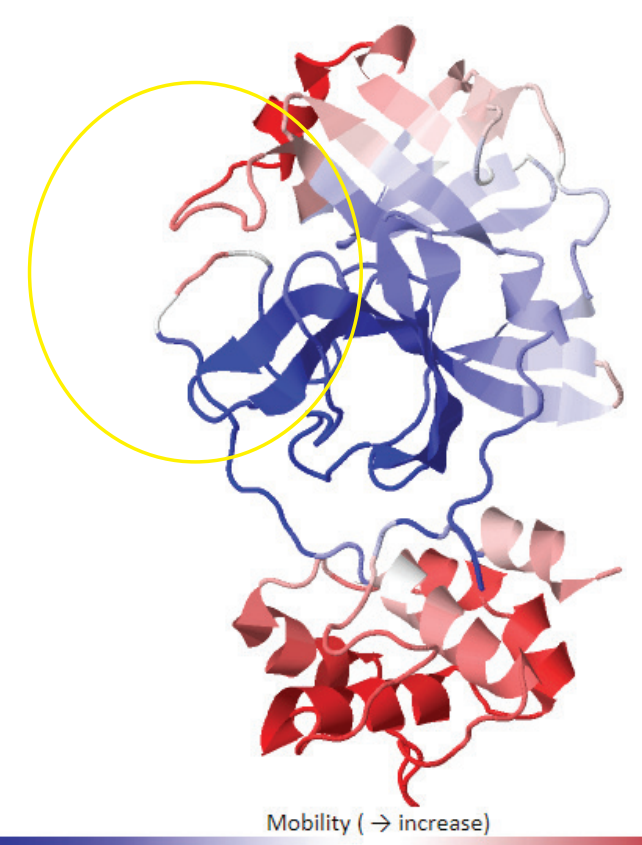

SARS-CoV proteinase

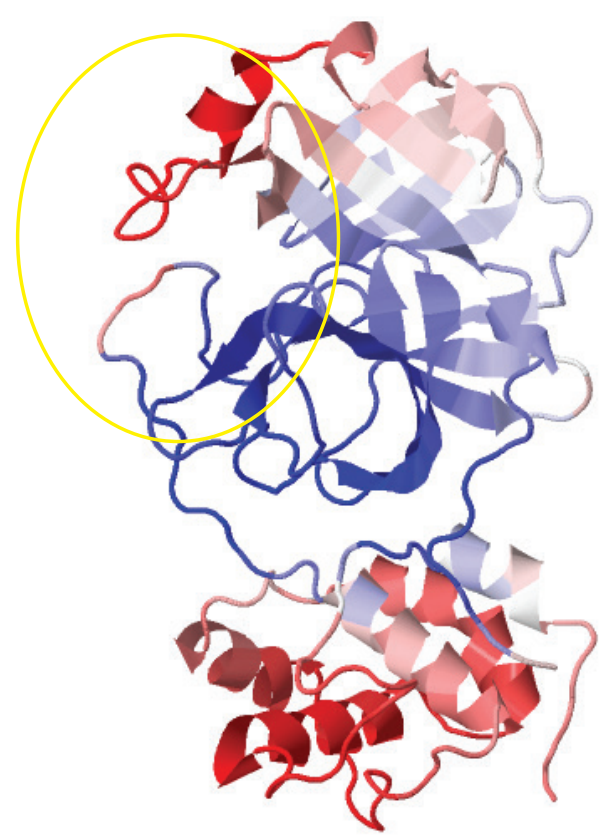

Mobility ( $\rightarrow$ increase)

COVID-19 proteinase 


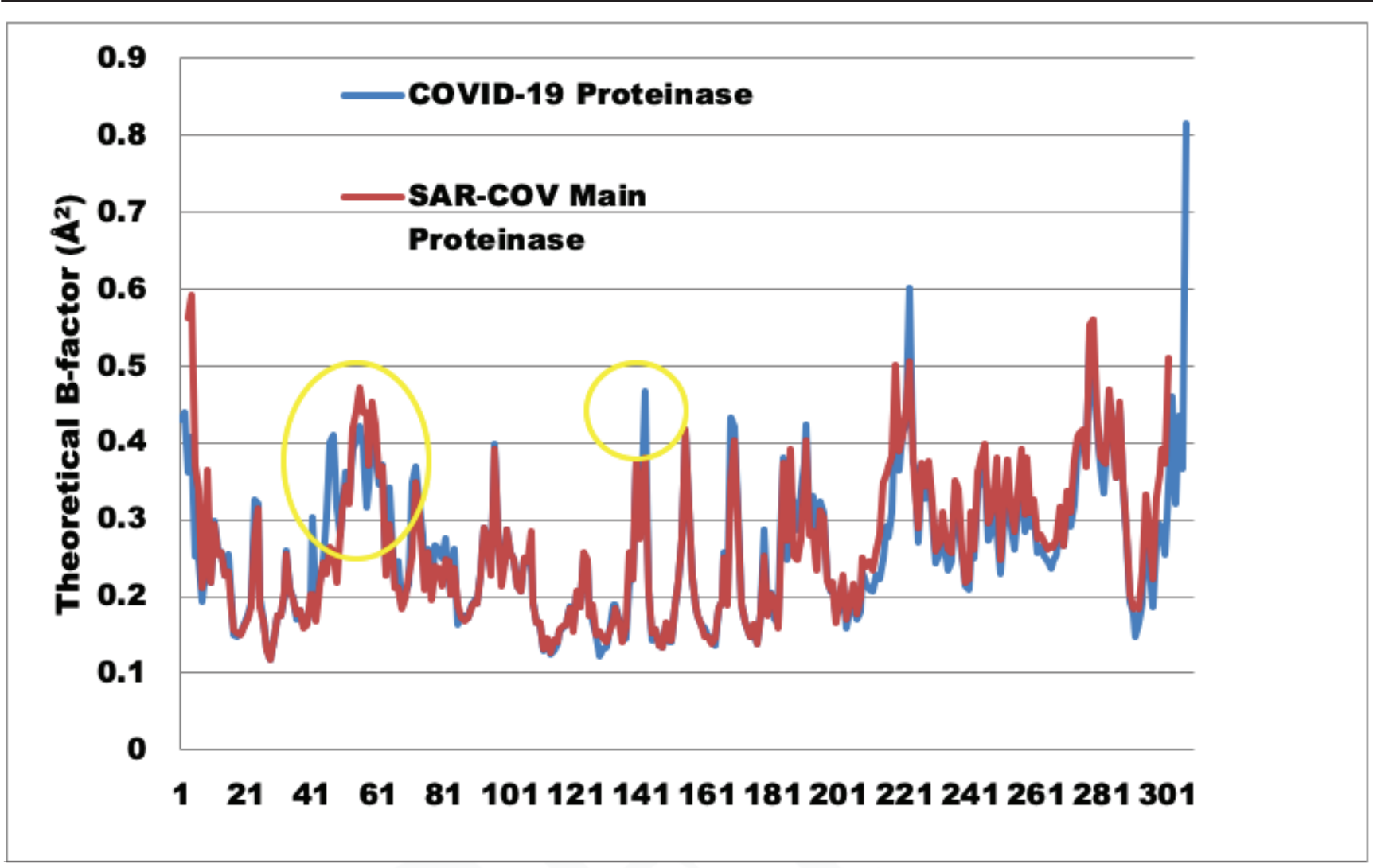

Figure 4. Theoretical B-factor indicate the mean-square fluctuation of residues. His41 and Cys 145 are the binding site centre and circled in yellow.

Table 3. Docking study of 67 approved drugs against COVID-19 proteinase.

\begin{tabular}{|c|c|c|c|}
\hline Ligand & Lowest Binding Energy (kcal/mol) & Ligand & Lowest Binding Energy (kcal/mol) \\
\hline \multicolumn{2}{|r|}{ Strong Interaction } & \multicolumn{2}{|r|}{ Weak Interaction } \\
\hline DB01601 & -8.7 & $\begin{array}{l}\text { DB00705 } \\
\text { DB00718 } \\
\text { DB01319 } \\
\end{array}$ & -6.9 \\
\hline $\begin{array}{l}\text { DB06290 } \\
\text { DB09183 }\end{array}$ & -8.4 & DB06414 & -6.8 \\
\hline DB01232 & -8.2 & $\begin{array}{l}\text { DB00442 } \\
\text { DB00900 } \\
\text { DB01048 } \\
\text { DB00468 }\end{array}$ & -6.7 \\
\hline $\begin{array}{l}\text { DB00220 } \\
\text { DB14761 } \\
\text { DB00254 } \\
\text { DB01117 }\end{array}$ & -8.1 & $\begin{array}{l}\text { DB01610 } \\
\text { DB00908 }\end{array}$ & -6.6 \\
\hline $\begin{array}{l}\text { DB04835 } \\
\text { DB08930 }\end{array}$ & -8.0 & $\begin{array}{l}\text { DB00577 } \\
\text { DB08873 } \\
\text { DB13132 }\end{array}$ & -6.5 \\
\hline
\end{tabular}




\begin{tabular}{|c|c|c|c|}
\hline $\begin{array}{l}\text { DB00224 } \\
\text { DB06817 }\end{array}$ & -7.9 & $\begin{array}{l}\text { DB00787 } \\
\text { DB00613 } \\
\text { DB01299 } \\
\end{array}$ & -6.4 \\
\hline DB08864 & -7.8 & $\begin{array}{l}\text { DB00426 } \\
\text { DB00432 } \\
\text { DB00558 } \\
\text { DB00811 } \\
\text { DB00207 } \\
\text { DB01131 }\end{array}$ & -6.3 \\
\hline $\begin{array}{l}\text { DB01264 } \\
\text { DB00759 }\end{array}$ & -7.7 & $\begin{array}{l}\text { DB00194 } \\
\text { DB00299 } \\
\text { DB00495 }\end{array}$ & -6.2 \\
\hline DB08934 & -7.3 & $\begin{array}{l}\text { DB00238 } \\
\text { DB01004 } \\
\text { DB01190 }\end{array}$ & -6.1 \\
\hline $\begin{array}{l}\text { DB01072 } \\
\text { DB05521 }\end{array}$ & -7.2 & $\begin{array}{l}\text { DB00625 } \\
\text { DB01087 }\end{array}$ & -6.0 \\
\hline $\begin{array}{l}\text { DB00503 } \\
\text { DB00701 } \\
\text { DB00358 } \\
\text { DB01218 }\end{array}$ & -7.0 & $\begin{array}{l}\text { DB00198 } \\
\text { DB00369 }\end{array}$ & -5.9 \\
\hline & & DB00943 & -5.8 \\
\hline & & $\begin{array}{l}\text { DB01265 } \\
\text { DB00205 }\end{array}$ & -5.7 \\
\hline & & $\begin{array}{l}\text { DB00249 } \\
\text { DB00879 }\end{array}$ & -5.5 \\
\hline & & $\begin{array}{l}\text { DB06614 } \\
\text { DB00608 }\end{array}$ & -5.4 \\
\hline & & $\begin{array}{l}\text { DB00649 } \\
\text { DB00709 }\end{array}$ & -5.3 \\
\hline & & DB12466 & -4.9 \\
\hline & & DB00478 & -4.8 \\
\hline & & DB00915 & -4.4 \\
\hline & & DB00529 & -4.3 \\
\hline
\end{tabular}

Note: The drugs in highlighted were reported as the current treatment for patients infected with the novel coronavirus. 
In consideration of intermolecular interactions in drugs against COVID-19 proteinase, results from the Autodock Vina using local search algorithm for virtual screening are shortlisted based on the lowest docking energy score along with the capability of the drug making a chemical interaction with the His41 and Cys145 (Table 3 \& Figure 5) . Among effective approved drugs in this virtual screening, antiviral lopinavir (DB01601) bound best toward COVID-19 proteinase with a promising lowest binding energy of $-8.7 \mathrm{kcal} / \mathrm{mol}$, followed by Nelfinavir (DB00220), Remdesivir (DB14761), Ritonavir (DB00503), respectively. However, Oseltamivir (DB00198), Chloroquine (DB00608) and Favipiravir (DB12466) considered having a weaker interaction with respect to binding site. Their effectiveness may be due to the interaction with other receptor targets.

a)

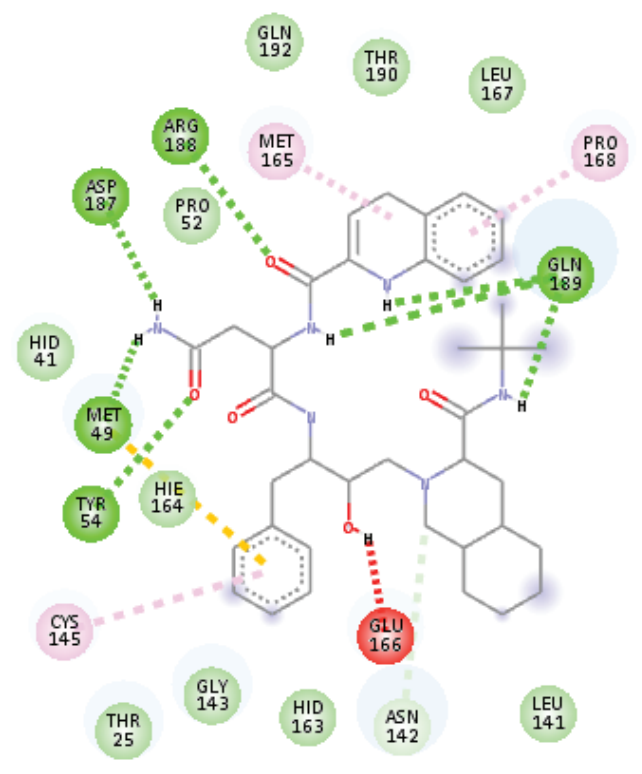

PHE
140

c)

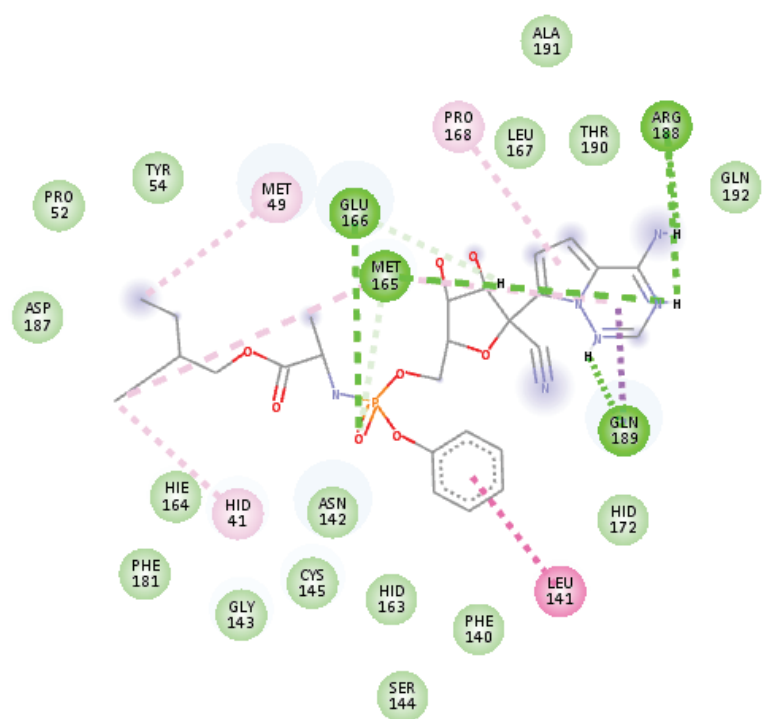

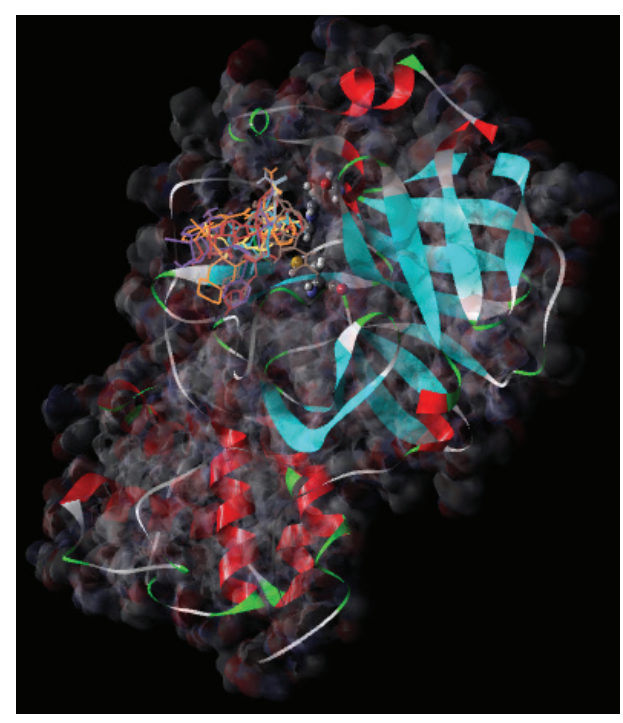

Figure 5. Seven current treatment drugs; lopinavir (DB01601, orange), Nelfinavir (DB00220, grey), Remdesivir (DB14761, purple), Ritonavir (DB00503, pink), Oseltamivir (DB00198, yellow), Chloroquine (DB00608, blue) and Favipiravir (DB12466, white). in stick model in binding with the binding pocket of COVID-19 proteinase. His 41 and Cys 145 binding site were in ball and stick model.

b)

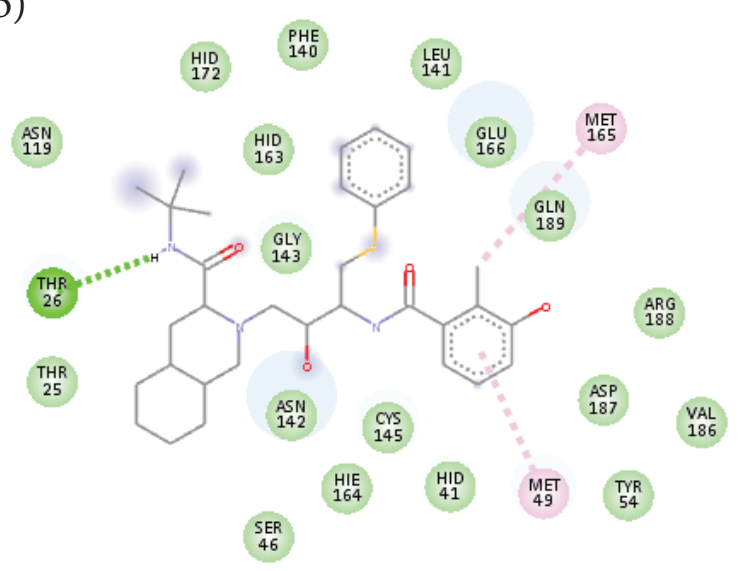

d)

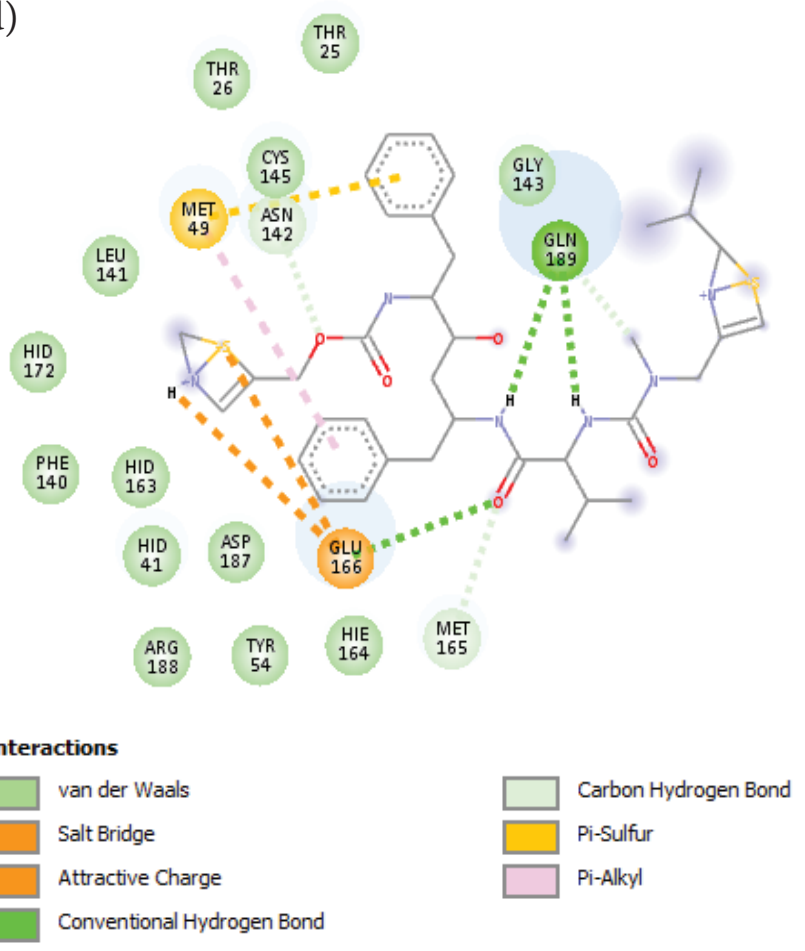

Figure 6. Schematic representation of the binding interactions between COVID-19 proteinase and a) Lopinavir (DB01601), b) Nelfinavir (DB00220), c) Remdesivir (DB14761) and d) Ritonavir (DB00503) (within $4.0 \AA$ ). Hydrogen bonds interactions are depicted with green dotted lines. 
To explore contributing interactions in the active sites of high potent drugs, the possible binding interactions between COVID-19 proteinase and currently used antiviral drugs lopinavir (DB01601), Nelfinavir (DB00220), Remdesivir (DB14761) and Ritonavir (DB00503) were mapped into 2D diagram using PoseView as shown in Figure 6. Residues i.e., Thr26, Met49, Tyr54, Met165, Glu166, Asp187, Arg 188 and Gln189 were involved in hydrogen bonding whereas residues such as His41, Met49, Cys145, Met165 and Pro168 were contributed to to alkyl and pi-alkyl interactions. Additionally, the analysis have indicated that some van der Waals interactions were found between these drugs and the binding residues Thr25, Thr26, His41, Ser46, Tyr54, Pro52, Asn119, Phe140, Leu141, Asn142, Gly143, Ser144, Cys145, His163, His164, Met165, Glu166, Leu167, His172, Leu167, Phe181, Val186, Asp187, Arg188, Thr190, Ala191 and Gln192. Further investigations using PoseView (Figures are not shown) have revealed that residues such as Thr25, Met49, Leu141, Glu166, Met165, Met168, Asp187 and Gln189 were due to non-polar interactions. Based on these observations, 7 new potential drug candidates, DB06290 (Simeprevir, Hepatitis C drug), DB09183 (Dasabuvir, Hepatitis C drug), DB01232 (Saquinavir, HIV-1 drug), DB00254 (Doxycycline, Malaria drug), DB01117 (Atovaquone, Malaria drug), DB04835(Maraviroc, HIV-1 drug), DB08930 (Dolutegravir, Hepatitis C drug) which have the favourable interactions similar to the current treatment drug $(<-8.0 \mathrm{kcal} / \mathrm{mol})$ can be further studied experimentally.

\section{Conclusion}

In order to search for potent COVID-19 drugs, molecular docking studies of 67 approved drug were explored and preliminary results show that the binding affinities for current treatment drug toward coronavirus proteinase were -8.7 to $-4.9 \mathrm{kcal} / \mathrm{mol}$. Sequence alignment and binding site flexibility indicate the different binding mode of interaction between SARS-CoV and COVID-19. From our results, lopinavir bound best to COVID-19 protienase and in silico screening suggests seven more potential FDA approved drugs for HIV-1, hepatitis C and malaria which can be repurposed and further investigated experimentally.

\section{Conflict of Interest}

The authors declare that there is no conflict of interest.

\section{Acknowledgements}

The authors thank Fundamental Research Grant Scheme (FRGS): FP125-2019A for funding to conduct this study.

\section{Reference}

1. Granlinski LE, Menachery VD. Return of the Coronavirus: 2019nCoV. Viruses 2020; 12(135): 1-8.

2. Coronavirus updates: Dangerous disease now called COVID-19; death toll exceeds 1,100. The New York Times 2020. Available from: https://www.nytimes.com/2020/02/12/world/asia/coronavirus-chinacovid-19.html).

3. Rapid outbreak response requires trust. Nat Microbiol 2020. Available from: https://doi.org/10.1038/s41564-020-0670-8

4. Virological.org. Novel 2019 coronavirus genome. Available from: https://virological.org/t/novel-2019-coronavirus-genome/319 [Accessed 10th February 2020].

5. GSAID Database. 2020 Coronavirus. Available from: https://www gisaid.org/CoV2020/ [Accessed 10th February 2020]

6. Munster VJ, Koopmans M, van Doremalen N, et al. A novel coronavirus emerging in China - Key questions for impact assessment. N Engl J Med 2020; https://doi.org/10.1056/NEJMp2000929.

7. Lu R, Zhao X, Li J. et al. Genomic characterization and epidemiology of 2019 novel coronavirus: Implications for virus origins and receptor binding. The Lancet 2020; 395(10224): 565-574.

8. Pangolins are suspected as a potential coronavirus host. Available from: https://www.nytimes.com/2020/02/10/science/pangolin-coronavirus.html [Accessed 12th February 2020].

9. Letchumanan V, Ab Mutalib N-S, Goh B-H, et al. Novel Coronavirus 2019-nCoV: Could this virus become a possible global pandemic. Prog Microbes Mol Biol 2020 3(1): a0000068. htps://doi.org/10.36877/ pmmb.a0000068.

10. Novel coronavirus: Total cases so far (update daily). Available from: https://www.thestar.com.my/news/nation/2020/01/26/the-rapid-global-spread-of-the-novel-coronavirus---total-cases-so-far\# [Accessed 12th February 2020].

11. 2019 coronavirus outbreak. Worldometer 2020. (Available from: https:// https://www.worldometers.info/coronavirus/ [Accessed 12th February 2020).

12. Coronavirus: New study finds incubation period up to 24 days. Available from: https://www.thestar.com.my/news/regional/2020/02/11 coronavirus-new-study-finds-incubation-period-of-up-to-24-days; [Accessed 11th February 2020].

13. VP infected; Saudi halts pilgrimage: All the latest updates. Available from: https://www.aljazeera.com/news/2020/02/trump-ready-coronavirus-live-updates-200226235731205.html; [Accessed on 28th February 2020].

14. Coronavirus spreads in Middle East and beyond: Live updates. Available from: https://www.aljazeera.com/news/2020/02/china-coronavirus-outbreak-latest-updates-200226003835539.html [Accessed 28th February 2020].

15. Genome giant BGI gets regulatory approval to sell coronavirus test kits. CXTech 2020. Available from: https://www.caixinglobal com/2020-01-29/genome-giant-bgi-gets-regulator-approval-to-sellcoronavirus-test-kits-101509268.html; [Accessed 1st February 2020].

16. Coronavirus: Thailand has apparent treatment success with antiviral drug cocktail. South China Morning Post 2020. Available from: https://www.scmp.com/news/asia/southeast-asia/article/3048629/ coronavirus-thailand-has-apparent-treatment-success [Accessed 2nd February 2020]

17. COVID-19 in Malaysia: List of patients who have recovered. Available from: https://www.channelnewsasia.com/news/asia/covid 19-malaysia-list-of-patients-recovered-discharged-12441998 [Accessed 2nd February 2020]

18. Coronavirus case in the US treated with experimental Gilead drug may spur wider tests. South China Morning Post 2020. Available from: https://www.scmp.com/tech/science-research/article/3048579/ coronavirus-case-us-treated-experimental-gilead-drug-may-spur [Accessed 3rd February 2020]

19. Available from: https://www.the-scientist.com/news-opinion/flu-andanti-hiv-drugs-show-efficacy-against-coronavirus-67052 [Accessed 12th February 2020].

20. Coronavirus: Thailand doctors use HIV plus flu drugs. (Available from: https://www.pharmaceutical-technology.com/news/coronavirus-thailand-treatment-combo/ [Accessed 12th February 2020].

21. Available from: https://www.thestar.com.my/news/regional/2020/02/18/chinese-experts-confirm-antimalarial-drug-is-effectiveon-covid-19-infection [Accessed 20th February 2020].

22. Lee VS, Wittayanarakul K, Remsungnen T, et al. Structure and dynamics of SARS coronavirus proteinase: The primary key to the designing and screening for anti-SARS drugs. Sci Asia 2003; 29:181-188.

23. Case DA, Babin V, Berryman JT, et al. AMBER 14, University of California, San Francisco, 2014.

24. Bahar I, Atilgan AR, Erman, B. Direct evaluation of thermal fluctuations in proteins using a single-parameter harmonic potential. Folding Des 1997; 2: 173-181

25. Bahar I, Erman B, Haliloglu T, et al. Efficient characterization of collective motions and interresidue correlations in proteins by low-resolution simulations. Biochem 1997; 36: 13512-13523.

26. Tirion MM. Large Amplitude Elastic Motions in Proteins from a Single-Parameter,

27. Atomic Analysis. Phys Rev Lett 1996; 77: 1905-1908.

28. Wishart DS, Knox C, Guo AC, et al. DrugBank: a comprehensive resource for in silico drug discovery and exploration. Nucleic Acids Res 2006; 34: D668-672.

29. Stierand K, Maaß P, Rarey M. Molecular Complexes at a Glance: Automated Generation of two-dimensional Complex Diagrams. J. Bioinform 2006; 22: 1710-1716. 